\title{
An Updated Overview of Low Back Pain Management
}

\author{
Jae-Young Hong ${ }^{1}$, Kwang-Sup Song ${ }^{2}$, Jae Hwan Cho ${ }^{3}$, Jae Hyup Lee ${ }^{4}$, Nack Hwan Kim ${ }^{5}$ \\ ${ }^{I}$ Department of Orthopedics, Korea University Ansan Hospital, Ansan, Korea \\ ${ }^{2}$ Department of Orthopaedic Surgery, Chung-Ang University College of Medicine, Seoul, Korea \\ ${ }^{3}$ Department of Orthopedic Surgery, Asan Medical Center, University of Ulsan College of Medicine, Seoul, Korea \\ ${ }^{4}$ Department of Orthopedic Surgery, SMG-SNU Boramae Medical Center, Seoul, Korea \\ ${ }^{5}$ Department of Physical Medicine and Rehabilitation, Korea University Ansan Hospital, Ansan, Korea
}

We aimed to determine the recommendation level for the treatment of acute and chronic low back pain (LBP). A systematic review (SR) of the literature was performed and all English-language articles that discuss acute and chronic LBP, including MEDLINE and the Cochrane Database of Systematic Reviews, were searched. Of the 873 searched literature reports, 259 articles, including 131 clinical trials, 115 SRs, nine meta-analyses, and four clinical guidelines were analyzed. In these articles, high-quality randomized controlled trials, SRs, and used well-written clinical guidelines were reviewed. The results indicated multiple acute and chronic LBP treatment methods in the literature, and these reports when reviewed included general behavior, pharmacological therapy, psychological therapy, specific exercise, active rehabilitation and educational interventions, manual therapy, physical modalities, and invasive procedures. The Trial conclusions and SRs were classified into four categories of A, B, C, and D. If there were not enough high-quality articles, it was designated as "I" (insufficient). This review and summary of guidelines may be beneficial for physicians to better understand and make recommendations in primary care.

Keywords: Low back pain; Treatment guidelines; Recommendations

\section{Introduction}

The lifetime prevalence of low back pain (LBP) is over $70 \%$ in industrialized countries with a worldwide lifetime prevalence of $84 \%[1,2]$. Accordingly, many guidelines for treating LBP have been published in the past 20 years. Most of the current guidelines focus on the use of medications [3-6]. Acute and chronic LBP are completely different manifestations of pain that must be treated differently. Acute LBP is prevalent and may transition into chronic LBP, which is associated with reduced quality of life, pain, and disability [7]. Acute LBP can be treated conservatively at first and certain physical therapy approaches usually exacerbate rather than help the condition. To identify patients who are likely going to require more complex triage and prolonged therapies should be performed compared to those whose back pain would resolve spontaneously. Therefore, selective adoption of certain treatment modalities is required for physicians in the treatment of acute and chronic LBP.

We previously published preliminary guidelines for LBP that focused on medication in 2017 [8]. There were many limitations in it; thus, we thoroughly reviewed the comprehensive treatment modalities and approaches, then

Received Sep 15, 2021; Revised Nov 30, 2021; Accepted Dec 12, 2021

Corresponding author: Jae-Young Hong

Department of Orthopedics, Korea University Ansan Hospital, 123 Jeokgeum-ro, Danwon-gu, Ansan 15355, Korea

Tel: +82-31-412-6577, Fax: +82-31-487-9502, E-mail: osspine@korea.ac.kr 
graded the approach accordingly, which focused on general behavior, pharmacological and psychological therapy, exercise, rehabilitation, educational intervention, physical modalities, and invasive procedures [9]. We reviewed the previous guidelines and perused high-quality articles to determine the recommendations for acute as well as chronic conditions with multiple treatment modalities. This review may enhance the recommendations in the current guidelines regarding LBP treatment.

\section{Methods}

\section{Data sources and searches}

We searched articles on acute and chronic LBP, including the MEDLINE database and the Cochrane Database of Systematic Reviews for relevant reviews. A comprehensive literature search was conducted from 1980 to 2019. The inclusion criteria were studies with LBP but studies on LBP associated with neuropathic pain were excluded. We also excluded reviews that were outdated and did not use clear systematic methods and systematic reviews (SRs) that evaluated target medications but did not report targeted results for patients with LBP. Our primary source for trials was the review of clinical guidelines, SRs, and meta-analyses because of the large number of trials that have evaluated medications for LBP. Additionally, searches for highquality randomized controlled trials (RCTs), particularly when there was insufficient data for treatment modalities, were conducted. Institutional review board approval was not necessary for this study at Korea University Ansan Hospital.

\section{Data extraction}

An expert panel determined the treatments to be included in this review. Data were subsequently abstracted by reviewers and thereby verified. For each trial, acute LBP (less than 4 weeks in duration) and chronic/subacute LBP (greater than 4 weeks in duration) were differentiated. If specific data on the duration of trials were not provided, the categorization (acute or chronic/subacute) assigned by the articles was relied upon.

\section{Quality assessment}

Internal validity, including the quality of SRs, was assessed by the Scottish Intercollegiate Guidelines Network criteria [10]. The Methodology Checklist can be applied to six different types comprising of SRs, RCTs, observational studies, diagnostic studies, economic studies, and patient issues. After the assessment of validity, the overall assessment was evaluated using three options. Two independent raters (J.Y.H. and J.H.C.) then conducted the quality assessment.

\section{Analysis of evidence and recommendations}

The analysis of evidence and recommendations followed the Systems to Rate the Strength of Scientific Evidence of the Agency for Healthcare Research and Quality [10]. The evidence in each article was categorized from $1++$ (which is most highly qualified) to 4 (which is most poorly qualified). Recommendation grades for treatment modalities were determined in the expert panel discussion consistent with the strength of the evidence. Conclusions of the trials and SRs were classified as A, B, C, and D. If there were not enough numbers of high-quality articles, it was classified as insufficient (I) (Table 1). The final verdict regarding the recommendation grade using each approach was obtained according to the agreement of the four raters (J.Y.H., J.H.L., K.S.S., and J.H.L.)

\section{Results}

Out of the 873 searched literature reports, 869 abstracts of those articles were reviewed; 427 articles were excluded after reviewing the abstract. The remaining 442 articles were reviewed by the study panel group during which 187 articles were excluded after quality evaluation. In summary, 259 articles including 131 clinical trials, 115 SRs, nine meta-analyses, and four clinical guideline reviews were analyzed. In these articles, the high-quality RCTs, SRs, and well-written clinical guideline reviews were reviewed (Fig. 1).

\section{General behavior}

A variety of acute and chronic LBP treatment methods are seen in the literature and these methods were reviewed accordingly (Table 2). Four trials found that effective treatment included education in addition to self-care and also recommendations for multiple activities for patients that had acute LBP. Furthermore, we found three posi- 
Table 1. Analysis of evidence and recommendations

\begin{tabular}{|c|c|}
\hline & Contents \\
\hline \multicolumn{2}{|c|}{ Criteria for quality assessment } \\
\hline++ & All or most standards are met. It is certain that the results of the study will not be changed by the unmet standards. \\
\hline+ & Some of the standards are met. The results of the study will not likely be changed by the unmet standards. \\
\hline- & All or most standards are not met. The results of the study may be changed by the unmet standards. \\
\hline \multicolumn{2}{|c|}{ Degree of evidence } \\
\hline $1++$ & $\begin{array}{l}\text { - High quality meta-analysis and systematic review conducted by randomized clinical trials } \\
\text { - Randomized controlled trials with a very low risk of bias }\end{array}$ \\
\hline $1+$ & $\begin{array}{l}\text { - Well-designed meta-analysis and systematic review conducted by randomized or non-randomized clinical trials } \\
\text { - Randomized or non-randomized clinical trials with a low risk of bias }\end{array}$ \\
\hline $1-$ & $\begin{array}{l}\text { - Meta analysis and systematic review conducted by randomized or non-randomized clinical trials } \\
\text { - Randomized or non-randomized clinical trials with a high risk of bias }\end{array}$ \\
\hline $2++$ & $\begin{array}{l}\text { - High-quality systematic review conducted using a patient control study, cohort study, or diagnosis analytic study } \\
\text { - High-quality patient control study, cohort study, or diagnosis analytic study with a very low risk of confounding, bias or contin- } \\
\text { gency, or a high possibility of cause and effect relationship }\end{array}$ \\
\hline $2+$ & $\begin{array}{l}\text { - High-quality patient control study, cohort study, or diagnosis analytic study with a low risk of a confounding, bias or contingency, } \\
\text { or the normal possibility of a cause and effect relationship }\end{array}$ \\
\hline 2- & $\begin{array}{l}\text { - Patient control study, cohort study, or diagnosis analytic study with a high risk of a confounding bias or contingency, or the low } \\
\text { possibility of a cause and effect relationship }\end{array}$ \\
\hline 3 & - Non-analytic studies, e.g., before-and-after study, case series, case report \\
\hline 4 & - Expert opinion \\
\hline \multicolumn{2}{|c|}{ Recommendation grade } \\
\hline A & $\begin{array}{l}\text { - One or more meta-analyses or systematic reviews or 1++ randomized, controlled trials that (if applicable) target the population } \\
\text { directly } \\
\text { - Mainly } 1+\text { studies are included, it is directly applicable to the target population, and the result shows overall consistency }\end{array}$ \\
\hline B & $\begin{array}{l}\text { - Mainly } 2++ \text { studies are included, it is directly applicable to the target population, and the result shows overall consistency } \\
\text { - If the evidence is presumed by } 1++ \text { or } 1+\text { studies }\end{array}$ \\
\hline C & $\begin{array}{l}\text { - Mainly } 2+\text { studies are included, it is directly applicable to the target population, and the result shows overall consistency } \\
\text { - If the evidence is presumed by } 2++ \text { studies }\end{array}$ \\
\hline$D$ & $\begin{array}{l}\text { - Evidence } 3 \text { or } 4 \\
\text { - If the evidence is presumed by } 2+\text { studies }\end{array}$ \\
\hline
\end{tabular}

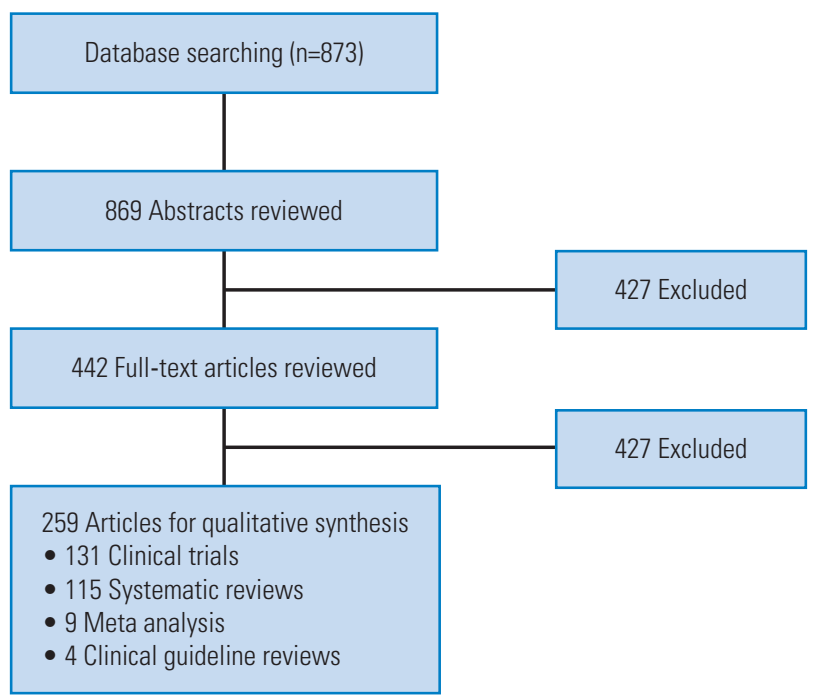

Fig. 1. Flow chart of article selection process.
Table 2. Recommendation grade for general behavior

\begin{tabular}{lcc} 
General behavior $[3,4,6,11-14]$ & Acute LBP & Chronic LBP \\
\hline Information & I & A \\
\hline Education \& self-care & A & A \\
\hline Advice to stay active & A & A \\
Reassure patients & A & B \\
\hline Bed rest & D & A \\
Modified work & I & I \\
\hline
\end{tabular}

LBP, low back pain; A, strongly support a recommendation for use; B, moderately support a recommendation for use; $\mathrm{C}$, marginally support a recommendation for use; D, support a recommendation against use; I, cannot determine the recommendation grade due to insufficient evidence. 
tive clinical guidelines, which strongly support the LBP improvement while reassuring patients and guiding acute LBP [4,6,11-14]. However, sufficient evidence for bed rest and modified work recommendations were not found. For chronic LBP, two higher-quality trials, which showed evidence for education, self-care, and recommendations for staying active were acquired $[3,4,12,13]$. Moreover, two clinical guidelines that strongly support reassuring patients and bed rest for treating chronic LBP were attained.

\section{Pharmacologic therapy}

Multiple higher-quality trials, SRs, and numerous clinical guidelines have demonstrated improvement with nonsteroidal anti-inflammatory drugs (NSAIDs) acetaminophen (AAP), and paracetamol for acute LBP [15-24] (Table 3). Two trials and one clinical guideline reported minimal evidence for carisoprodol, herbal therapy, thiocolchicoside, and tizanidine $[6,16,18]$. Additionally, LBP improvement with opioids, benzodiazepines, muscle relaxants, and tricyclic antidepressants in two high-quality systemic

Table 3. Recommendation grade for pharmacologic therapy

\begin{tabular}{lcc}
\hline Pharmacologic therapy $[3-6,15-45]$ & Acute LBP & Chronic LBP \\
NSAIDs & A & A \\
\hline Acetaminophen & A & A \\
\hline Opioids & B & A \\
\hline Buprenorphine & I & A \\
\hline Benzodiazepines & B & B \\
\hline Antiepileptic drugs & B & C \\
\hline Aspirin & I & D \\
\hline Muscle relaxants & B & B \\
\hline Tricyclic antidepressants & B & B \\
\hline Systemic corticosteroids & I & I \\
\hline Tapentadol & I & B \\
\hline Glucosamine & I & D \\
\hline Adjunctive analgesics & I & I \\
\hline Carisoprodol & B & I \\
\hline Herbal therapy & B & I \\
\hline Thicolchicoside & B & B \\
\hline Tizanidine & B & I \\
\hline LP low back pan; & & B \\
\hline
\end{tabular}

LBP, low back pain; NSAIDs, non-steroidal anti-inflammatory drugs; $A$, strongly support a recommendation for use; $B$, moderately support a recommendation for use; $C$, marginally support a recommendation for use; $D$, support a recommendation against use; I, cannot determine the recommendation grade due to insufficient evidence. reviews and three clinical guidelines has been reported $[4-6,24]$. There were several higher-quality trials and SRs that support the pain improvement of NSAIDs, AAP, paracetamol, opioids, and buprenorphine in chronic LBP [3,4,6,17,21-45]. Benzodiazepines, muscle relaxants, tricyclic antidepressants, tapentadol, and pregabalin were supported by seven higher-quality studies and also three clinical guidelines reported improvement in symptoms $[3,4,6,39-45]$.

\section{Psychological therapy}

Two methods for treating acute and chronic LBP were included in this study (cognitive-behavioral therapy along with multidisciplinary treatment). No high-quality trials were found and general evidence from literature was insufficient to support the evidence of psychological therapy for acute LBP (Table 4). However, for chronic LBP, five high-quality trials reported pain improvement with cognitive-behavioral therapy [32,46-49]. Progressive muscle relaxation and multidisciplinary treatment were strongly supported by clinical guidelines, and the study methods were of a higher quality. Three clinical guidelines that strongly support the pain improvement of cognitivebehavioral therapy for chronic LBP were noticed $[3,5,6]$.

\section{Exercise}

We identified general exercise and ten specific exercises for acute and chronic LBP in the literature. For acute LBP, six trials of general behavior and two clinical guidelines were reviewed to determine the effects of general exercise $[4,6,50-54]$ (Table 4). The strategic method (action, sequence, use of tools, etc.), was defined as a specific exercise. After considering several trials and clinical guidelines, the results were insufficient to support pain improvement with the majority of specific exercises. Twelve higher-quality trials showed a significant difference in pain relief with general exercise for chronic LBP $[47,48,50,55-59]$. Consequently, it was determined the recommendation grade of general exercise based on two meta-analyses, three SRs, and three clinical guidelines for chronic LBP [3,4,6,60-64]. Seven trials, which supported stabilizing exercise for pain relief (which included two trials) and two clinical guidelines for aquatic and supervised exercise therapy were noted [3,5,34,46,65-71]. Moreover, one higher-quality trial, one meta-analysis, and two clini- 
Table 4. Recommendation grade for psychological therapy and exercise

Variable Acute LBP Chronic LBP

Psychological therapy $[3,5,6,32,46-49]$

\begin{tabular}{|lll}
\hline Cognitive behavioral therapy & I & B \\
\hline Multidisciplinary treatment & I & B \\
\hline Exercise $[4,6,50-54]$ & & A \\
\hline General & C & \\
\hline Specific exercise ${ }^{\text {al) }}[3,4,6,47,48,50,55-64,72,73]$ & & C \\
\hline Mobilizing & I & C \\
\hline Strengthening & I & C \\
\hline Unsupervised walking & I & C \\
\hline Core stability & I & C \\
\hline Mckenzie & C & B \\
\hline Supervised exercise & D & B \\
\hline Balance exercise & C & C \\
\hline Stretching & C & B \\
\hline Yoga & I & I \\
\hline Hydrotherapy & I & C \\
\hline Pilates & I & B \\
\hline
\end{tabular}

LBP, low back pain; $A$, strongly support a recommendation for use; $B$, moderately support a recommendation for use; $C$, marginally support a recommendation for use; D, support a recommendation against use; I, cannot determine the recommendation grade due to insufficient evidence.

al If there was a strategic method (action, sequence, use of tools, etc.) for a goal through exercise, the method is 'specific' exercise.

cal guidelines found that yoga was an effective treatment $[3,6,72,73]$. However, several of these treatments were not supported by trials or analysis.

\section{Multidisciplinary rehabilitation and educational in- terventions}

Mutidisciplinary and interdisciplinary rehabilitation, as well as educational treatment methods for acute and chronic LBP were reviewed [3-6,20,59,62,74-90]. For acute LBP, an insufficient number of trials for the eight treatment methods were noted; however, two clinical guidelines were included [4,6] (Table 5). Twelve trials reported clear differences in pain relief with active rehabilitation followed by educational interventions for chronic LBP [59,79-88]. Six randomized trials, one SR, and three clinical guidelines for multidisciplinary rehabilitation for chronic LBP were identified [3-5,62,79-84]. Besides, six higher-quality trials and three clinical guidelines supported pain improvement with back schools [3,4,6,59,79-88].
Table 5. Recommendation grade for multi- and interdisciplinary rehabilitation, educational interventions, and manual therapy

\begin{tabular}{lcc}
\hline Variable & Acute LBP & Chronic LBP \\
\hline Multi- and interdisciplinary rehabilitation [3-6] & & \\
\hline Multidisciplinary & A & A \\
\hline Interdisciplinary & I & A \\
\hline Educational interventions $[20,59,62,74-90]$ & & \\
\hline Brief educational & I & B \\
\hline CPP intervention & I & A \\
\hline Back schools & C & C \\
\hline Biofeedback & D & D \\
\hline Behavioral therapy & B & B \\
\hline Interferential current therapy ${ }^{\text {a) }}$ & I & I \\
\hline Manual therapy [3-6,20,47,62,67,74-78,90,92-96] & & \\
\hline Spinal manipulation & B & B \\
\hline Massage & C & B \\
\hline Chiropractic & C & B \\
\hline
\end{tabular}

LBP, low back pain; $A$, strongly support a recommendation for use; $B$, moderately support a recommendation for use; $C$, marginally support a recommendation for use; D, support a recommendation against use; I, cannot determine the recommendation grade due to insufficient evidence; CPP, Child-Parent Psychotherapy.

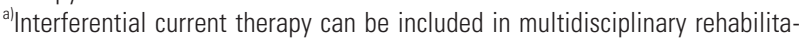
tion.

\section{Manual therapy}

We reviewed spinal manipulation, mobilization, massage, and chiropractic management for treating acute as well as chronic LBP. There was sufficient evidence from several RCTs along with clinical guidelines to support the improvement of pain in manual therapy in acute or chronic LBP [3-6,20,47,62,67,74-77,90-96] (Table 5). For acute LBP, spinal manipulations were supported by three high-quality trials, one SR, in addition to two clinical guidelines $[3,6,20,74,75,96]$. For chronic LBP, four higherquality trials, two SRs, as well as four clinical guidelines found evidence to support pain improvement with spinal manipulation [3-5,47,62,67,90,91,96]. Besides, three moderate quality trials supported pain improvement with chiropractic approaches for treating chronic LBP $[76,94,95]$.

\section{Physical modalities}

Methods for treating acute and chronic LBP were reviewed [3-6,48,49,68,72,73,78,97-111] (Table 6). For acute LBP, the evidence from several trials plus clinical guide- 
Table 6. Recommendation grade for physical modalities

\begin{tabular}{lcc} 
Physical modalities $[3-6,48,49,68,72,73,78,97-113]$ & Acute LBP & Chronic LBP \\
General & B & B \\
Heat/cold & B & C \\
\hline TENS & C & C \\
\hline Traction & C & C \\
Ultrasound & C & C \\
Electrical stimulation $^{\text {a) }}$ & I & D \\
\hline Short wave diathermy & I & I \\
Lower-level laser $^{\text {Physiotherapy }}$ & I & D \\
Acupuncture & C & B \\
\hline
\end{tabular}

LBP, low back pain; TENS, transcutaneous electrical nerve stimulation; $A$, strongly support a recommendation for use; $B$, moderately support a recommendation for use; $C$, marginally support a recommendation for use; D, support a recommendation against use; I, cannot determine the recommendation grade due to insufficient evidence.

${ }^{a}$ Neuromuscular electrical stimulation excluding TENS.

lines was insufficient to support pain improvement with the majority of physical modalities. One systemic review together with two clinical guidelines were included in the review of heat and cold therapy for acute LBP $[4,6,49]$. For chronic LBP, one higher-quality randomized trial supported pain improvement from general physical modalities $[3,6,72,73,98]$. Higher-quality trials, a SR, and three clinical guidelines that supported acupuncture for treating chronic LBP were observed $[3,4,6,112,113]$. Nevertheless, there was insufficient evidence for a majority of treatment methods for chronic LBP.

\section{Invasive procedures}

Methods for treating acute and chronic LBP were reviewed with invasive procedures (Table 7). There was insufficient evidence for the greater part of treatment methods for acute LBP $[3,4,6,24,54,112-127]$. There was a SR and another clinical guideline that supported an epidural steroid injection for treating acute LBP $[4,24]$. For chronic LBP, numerous clinical trials reported a variety of invasive treatments $[3,4,6,112,113,127]$. Furthermore, three higher-quality trials, one meta-analysis, one SR, and two clinical guidelines supported pain improvement with epidural steroid injection $[3,4,24,116-118,126]$. Nonetheless, there was insufficient evidence for surgery as a treatment for chronic LBP.
Table 7. Recommendation grade for invasive procedures

\begin{tabular}{lcc}
\hline Invasive procedures $[3,4,6,24,54,112-127]$ & Acute LBP & Chronic LBP \\
\hline Prolotherapy & I & C \\
\hline IDET/nucleoplasty & D & C \\
\hline Spinal cord stimulation & C & C \\
\hline TC electrical stimulation & I & D \\
\hline Epidural steroid injection & B & B \\
\hline TFESI & C & C \\
\hline Facet joint injection & C & C \\
\hline Intra-discal injection & I & C \\
\hline $\begin{array}{l}\text { Intra-discal toxicoderon } \\
\text { Soft tissue injections }\end{array}$ & I & D \\
\hline IM steroid & C & C \\
\hline Referral to surgery & C & D \\
\hline $\begin{array}{l}\text { Decompression } \\
\text { Fusion }\end{array}$ & I & B \\
\hline LBP, low back pain; IDET, intra-discal electrothermal therapy; TFESI, transfo- \\
raminal epidural steroid injection; A, strongly support a recommendation for \\
$\begin{array}{l}\text { use; B, moderately support a recommendation for use; C, marginally support a } \\
\text { recommendation for use; D, support a recommendation against use; I, cannot } \\
\text { determine the recommendation grade due to insufficient evidence. }\end{array}$ \\
\hline
\end{tabular}

\section{Discussion}

Presently, there are various guidelines for treating LBP that have been published by professional committees, which have provided unpredictable types of recommendations. These study groups have adopted different weighting systems and several types of evidence to support present recommendations [3-6,128-132]. Common recommendations include diagnostic steps for patients with LBP, minimal use of radiographs, support of progressive activation, and opposition to bed rest. Nevertheless, many clinical guidelines have focused on pharmaceutical treatments, physical therapy settings, or specific subgroups of patients with radicular pain. Selected clinical guidelines have focused on secondary care, which includes occupational care of patients with radicular pain that is related to compression of the spinal nerves. Conversely, careful diagnostic differentiation is required; in primary care, diagnostic triage of LBP is the anchor for a diagnosis. Focused history and clinical examination are the initial steps, followed by subsequent workup and referral to medical specialist is the next step. The main goal of diagnostic triage of LBP is to exclude nonspinal causes in addition to allocating patients to one of three broad categories: specific 
spinal pathology $(<1 \%)$, radicular syndrome $(5 \%-10 \%)$ or nonspecific LBP, which represents $90 \%-95 \%$ of cases and is diagnosed by exclusion of the first two categories [133]. For specific spinal pathologies (e.g., vertebral fracture, malignancy, infection, axial spondyloarthritis, or cauda equina syndrome), a clinical assessment with computed tomography (CT) or magnetic resonance imaging (MRI) may reveal the key alerting features $[134,135]$.

In this study, key treatment modalities and approaches that focused on general behavior, pharmacological therapy, psychological therapy, exercise, rehabilitation, educational intervention, physical modalities, and invasive procedures were reviewed. Although multiple clinical guidelines have reported insufficient evidence for surgical treatment, it does not eliminate the possibility that individual patients may benefit from surgical interventions. Additional guidance with appropriate surgical or interventional management is still needed, especially for chronic LBP and invasive procedures. Moreover, the duration of pain should be gravely considered in determining the recommendation level. As there are currently many different clinical guidelines, it was challenging to differentiate the treatment modalities for acute as well as chronic LBP. The published guidelines in addition to high-quality research articles to confirm recommendations for acute and chronic LBP were reviewed. Multiple treatment modalities, including invasive procedures for both acute and chronic LBP were also reviewed.

\section{General behavior \& pharmacologic therapy}

In terms of general behavior, many high-quality trials found that effective treatment included education, selfcare, and recommendations for activity for patients that had acute and chronic LBP. However, sufficient evidence was not found for improvement of pain with modified work. Further review is needed to confirm this recommendation. Physicians commonly apply pharmacological therapy with LBP and many higher-quality trials, SRs, and clinical guidelines with LBP improvement for NSAIDs, AAP for acute as well as chronic LBP were found. Many guidelines recommend that paracetamol should be used first and that nonsteroidal anti-inflammatory preparations can be used as a second course of treatment. Correspondingly, it was found that paracetamol and NSAIDs were associated with significant pain relief for acute and chronic LBP [15-24]. Moderate to high-quality trials that support the usage of benzodiazepines, muscle relaxants, tricyclic antidepressants, and thiocolchicoside with acute and chronic LBP were also noted. This group was given a grade B. An insufficient number of trials show improvement of pain with several medicines, and thus could not determine a recommendation grade for it. There is presently more evidence for second line drugs, including antidepressants, opioids, and benzodiazepines. However, these results are inconsistent with previous guidelines and reviews, showing a range of effectiveness with acute and chronic LBP. In terms of the duration of the pain, recommended drugs for acute LBP do not show similar effects for chronic LBP. Opioids and buprenorphine do not show similar pain improvements in the treatment of chronic LBP, which is beneficial to prevent opioid addiction in the LBP population. Otherwise, several drugs only showed pain relief in acute or chronic pain as a follow-up. There were multiple drugs with insufficient evidence to determine recommendation grades, which was a limitation of this study; further review is needed to confirm it.

\section{Psychological therapy \& exercise}

Cognitive-behavioral therapy and multidisciplinary treatment for chronic LBP are recommended. General and aerobic exercises were recommended for chronic LBP with less evidence of pain improvement in acute LBP. Guideline development committees have included content from other guidelines. For example, several trials found distinct differences in pain relief with general exercise for general LBP [47,48,50,55-59]. Nevertheless, due to the lack of specification, it could not be determined whether these treatment options were effective for chronic LBP. In terms of specific exercise recommendations, specific back exercises are not recommended with acute LBP in the majority of guidelines. Conversely, back exercises have been recommended in chronic LBP. In this study, we showed that general and supervised exercises are recommended for chronic LBP treatment but not for acute LBP treatment. However, a patient's severity of symptoms may determine whether or not it is available for acute pain. We moderately recommend supervised exercise, balanced exercise, and yoga for chronic LBP. In contrast, we could not determine a recommendation grade in a majority of specific exercises for acute LBP. There were multiple treatment modalities with insufficient evidence grades, which was a limitation. Although we found numerous specific 
exercises in trials and guidelines, high-quality articles strongly support that it was not available. Thus, further study is required to determine recommendations

\section{Disciplinary rehabilitation, educational interven- tions, and manual therapy}

We strongly recommended multidisciplinary and interdisciplinary rehabilitation for acute as well as chronic LBP. Even though there were insufficient trials this does not imply it should not be used. Consequently, physicians may expect pain improvement with disciplinary rehabilitation treatment in a clinical setting. Brief educational intervention, Child-Parent Psychotherapy intervention, and behavioral therapy were commended for chronic LBP with sufficient evidence but its use in acute LBP could not be determined. This is a limitation of our study, and further review is necessary for educational interventions in acute LBP treatment. Inappropriate beliefs and behaviors about acute LBP may induce as well as increase chronic pain; therefore, clinicians should recommend a combination of education and behavioral therapies [11-14]. Physicians can apply manual therapy in patients with acute and chronic LBP since it may be beneficial for certain groups of patients. Nevertheless, the evidence level was moderate to low and we gave this group grades $\mathrm{B}$ to $\mathrm{C}$ in this study.

\section{Physical modalities and invasive procedures}

General physical modalities were proposed in acute and chronic LBP. Nonetheless, there were a variety of specific physical modalities with insufficient evidence for use or were marginally recommended (grade B to C). We found several moderate to high-quality trials for the use of physiotherapy and acupuncture in chronic LBP. It was assigned as grade B. Conversely, sufficient evidence for improvement of pain with electrical stimulation, short wave diathermy, and lower-level laser treatment in acute LBP treatment were not noticed. Recently, various studies have been published with invasive procedures showing fair evidence, which may change the status with treatment of acute and chronic LBP $[3,4,6,112,113,127,136]$. Nonetheless, invasive procedures were not strongly suggested for LBP (grade C to D) and several trials for use of epidural steroid injection (grade B) were found in this study. Physicians can selectively refer patients to the surgical department (grade B) if chronic pain persists for a long time without any improvements. However, this does not mean surgical treatment is highly recommended for chronic LBP. These recommendations should be centered on assessments that exclude potentially serious spinal pathology or specific causes of LBP that may need surgical treatment. As a result, simple back pain and pathologic neuropathy with substantial neurologic involvement that could require an MRI or CT to confirm the diagnosis were separated. Invasive treatment may be needed to resolve the symptoms with spinal pathology.

\section{Limitation of the study}

We only focused on therapeutics, prevention (education), and rehabilitation in treatment of LBP. However, without a proper diagnosis of the LBP appropriate management cannot be instituted. Diagnostic triage is an essential recommendation for LBP, which is the most frequent musculoskeletal condition that general physicians encounter. In this study, differential diagnosis for red flag signs and indications for appropriate imaging procedures should have been included. Diagnostic triage in the updated overview for the management of LBP also could not be incorporated, which is a main limitation of the study.

\section{Conclusions}

High-quality trials and SRs were evaluated to assess the current recommendations for treating acute and chronic LBP. This review as well as the summary of guidelines may be beneficial for physicians to better understand and make recommendations for different degrees of LBP, particularly in primary care.

\section{Conflict of Interest}

No potential conflict of interest relevant to this article was reported.

\section{References}

1. van Tulder M, Becker A, Bekkering T, et al. Chapter 3. European guidelines for the management of acute nonspecific low back pain in primary care. Eur Spine J 2006;15(Suppl 2):S169-91.

2. Balague F, Mannion AF, Pellise F, Cedraschi C. Nonspecific low back pain. Lancet 2012;379:482-91. 
3. Pillastrini P, Gardenghi I, Bonetti F, et al. An updated overview of clinical guidelines for chronic low back pain management in primary care. Joint Bone Spine 2012;79:176-85.

4. Dagenais S, Tricco AC, Haldeman S. Synthesis of recommendations for the assessment and management of low back pain from recent clinical practice guidelines. Spine J 2010;10:514-29.

5. Koes BW, van Tulder M, Lin CW, Macedo LG, McAuley J, Maher C. An updated overview of clinical guidelines for the management of non-specific low back pain in primary care. Eur Spine J 2010;19:207594.

6. Chou R, Qaseem A, Snow V, et al. Diagnosis and treatment of low back pain: a joint clinical practice guideline from the American College of Physicians and the American Pain Society. Ann Intern Med 2007;147:478-91.

7. Panneerselvam K, Kanna RM, Shetty AP, Rajasekaran S. Impact of acute lumbar disk herniation on sexual function in male patients. Asian Spine J 2021 Nov 18 [Epub]. https://doi.org/10.31616/asj.2021.0083.

8. Hong JY, Song KS, Cho JH, Lee JH. An updated overview of low back pain management in primary care. Asian Spine J 2017;11:653-60.

9. Patel MS, Lee KC, Dhake RP, Longworth S, Sell P. Ability of spine specialists to identify psychosocial risk factors as obstacles to recovery in patients with low back pain-related disorders. Asian Spine J 2021;15:224-33.

10. Alonso-Coello P, Schunemann HJ, Moberg J, et al. GRADE Evidence to Decision (EtD) frameworks: a systematic and transparent approach to making well informed healthcare choices. 1: Introduction. BMJ 2016;353:i2016.

11. Pengel LH, Refshauge KM, Maher CG, Nicholas MK, Herbert RD, McNair P. Physiotherapist-directed exercise, advice, or both for subacute low back pain: a randomized trial. Ann Intern Med 2007;146:787-96.

12. Albaladejo C, Kovacs FM, Royuela A, del Pino R, Zamora J; Spanish Back Pain Research Network. The efficacy of a short education program and a short physiotherapy program for treating low back pain in primary care: a cluster randomized trial. Spine (Phila Pa 1976) 2010;35:483-96.

13. Liddle SD, Gracey JH, Baxter GD. Advice for the management of low back pain: a systematic review of randomised controlled trials. Man Ther 2007;12:31027.

14. Traeger AC, Hubscher M, Henschke N, Moseley GL, Lee H, McAuley JH. Effect of primary care-based education on reassurance in patients with acute low back pain: systematic review and meta-analysis. JAMA Intern Med 2015;175:733-43.

15. Lasko B, Levitt RJ, Rainsford KD, Bouchard S, Rozova A, Robertson S. Extended-release tramadol/ paracetamol in moderate-to-severe pain: a randomized, placebo-controlled study in patients with acute low back pain. Curr Med Res Opin 2012;28:847-57.

16. Ralph L, Look M, Wheeler W, Sacks H. Double-blind, placebo-controlled trial of carisoprodol 250-mg tablets in the treatment of acute lower-back spasm. Curr Med Res Opin 2008;24:551-8.

17. Perrot S, Krause D, Crozes P, Naim C; GRTF-ZAL-1 Study Group. Efficacy and tolerability of paracetamol/ tramadol (325 mg/37.5 mg) combination treatment compared with tramadol (50 $\mathrm{mg}$ ) monotherapy in patients with subacute low back pain: a multicenter, randomized, double-blind, parallel-group, 10-day treatment study. Clin Ther 2006;28:1592-606.

18. Ketenci A, Ozcan E, Karamursel S. Assessment of efficacy and psychomotor performances of thiocolchicoside and tizanidine in patients with acute low back pain. Int J Clin Pract 2005;59:764-70.

19. Williams CM, Maher CG, Latimer J, et al. Efficacy of paracetamol for acute low-back pain: a double-blind, randomized controlled trial. Lancet 2014;384:158696.

20. Hancock MJ, Maher CG, Latimer J, et al. Assessment of diclofenac or spinal manipulative therapy, or both, in addition to recommended first-line treatment for acute low back pain: a randomised controlled trial. Lancet 2007;370:1638-43.

21. Tetsunaga T, Tetsunaga T, Tanaka M, Ozaki T. Efficacy of tramadol-acetaminophen tablets in low back pain patients with depression. J Orthop Sci 2015;20:281-6.

22. Davies RA, Maher CG, Hancock MJ. A systematic review of paracetamol for non-specific low back pain. Eur Spine J 2008;17:1423-30.

23. Machado GC, Maher CG, Ferreira PH, et al. Efficacy and safety of paracetamol for spinal pain and osteoarthritis: systematic review and meta-analysis of randomised placebo controlled trials. BMJ 


\section{5;350:h1225.}

24. Nampiaparampil DE, Nampiaparampil GM, Nampiaparampil RG. Oral opioid analgesics vs. spinal steroid injections in the treatment of low back pain syndromes. Am J Phys Med Rehabil 2012;91:162-76.

25. Lee JH, Lee CS; Ultracet ER Study Group. A randomized, double-blind, placebo-controlled, parallelgroup study to evaluate the efficacy and safety of the extended-release tramadol hydrochloride/acetaminophen fixed-dose combination tablet for the treatment of chronic low back pain. Clin Ther 2013;35:1830-40.

26. Schiphorst Preuper HR, Geertzen JH, van Wijhe M, et al. Do analgesics improve functioning in patients with chronic low back pain?: an explorative tripleblinded RCT. Eur Spine J 2014;23:800-6.

27. Hale ME, Dvergsten C, Gimbel J. Efficacy and safety of oxymorphone extended release in chronic low back pain: results of a randomized, double-blind, placebo- and active-controlled phase III study. J Pain 2005;6:21-8.

28. Hale ME, Ahdieh H, Ma T, Rauck R; Oxymorphone ER Study Group 1. Efficacy and safety of OPANA ER (oxymorphone extended release) for relief of moderate to severe chronic low back pain in opioid-experienced patients: a 12-week, randomized, double-blind, placebo-controlled study. J Pain 2007;8:175-84.

29. Katz N, Rauck R, Ahdieh H, et al. A 12-week, randomized, placebo-controlled trial assessing the safety and efficacy of oxymorphone extended release for opioid-naive patients with chronic low back pain. Curr Med Res Opin 2007;23:117-28.

30. Vondrackova D, Leyendecker P, Meissner W, et al. Analgesic efficacy and safety of oxycodone in combination with naloxone as prolonged release tablets in patients with moderate to severe chronic pain. J Pain 2008;9:1144-54.

31. Cloutier C, Taliano J, O’Mahony W, et al. Controlledrelease oxycodone and naloxone in the treatment of chronic low back pain: a placebo-controlled, randomized study. Pain Res Manag 2013;18:75-82.

32. Nalamachu S, Rauck RL, Hale ME, Florete OG Jr, Robinson CY, Farr SJ. A long-term, open-label safety study of single-entity hydrocodone bitartrate extended release for the treatment of moderate to severe chronic pain. J Pain Res 2014;7:669-78.

33. Gordon A, Rashiq S, Moulin DE, et al. Buprenorphine transdermal system for opioid therapy in pa- tients with chronic low back pain. Pain Res Manag 2010;15:169-78.

34. Gordon A, Callaghan D, Spink D, et al. Buprenorphine transdermal system in adults with chronic low back pain: a randomized, double-blind, placebocontrolled crossover study, followed by an open-label extension phase. Clin Ther 2010;32:844-60.

35. Steiner DJ, Sitar S, Wen W, et al. Efficacy and safety of the seven-day buprenorphine transdermal system in opioid-naive patients with moderate to severe chronic low back pain: an enriched, randomized, double-blind, placebo-controlled study. J Pain Symptom Manage 2011;42:903-17.

36. Steiner D, Munera C, Hale M, Ripa S, Landau C. Efficacy and safety of buprenorphine transdermal system (BTDS) for chronic moderate to severe low back pain: a randomized, double-blind study. J Pain 2011;12:1163-73.

37. Miller K, Yarlas A, Wen W, et al. Buprenorphine transdermal system and quality of life in opioidexperienced patients with chronic low back pain. Expert Opin Pharmacother 2013;14:269-77.

38. Yarlas A, Miller K, Wen W, et al. A randomized, placebo-controlled study of the impact of the 7-day buprenorphine transdermal system on health-related quality of life in opioid-naive patients with moderateto-severe chronic low back pain. J Pain 2013;14:1423.

39. Katz J, Pennella-Vaughan J, Hetzel RD, Kanazi GE, Dworkin RH. A randomized, placebo-controlled trial of bupropion sustained release in chronic low back pain. J Pain 2005;6:656-61.

40. Wild JE, Grond S, Kuperwasser B, et al. Long-term safety and tolerability of tapentadol extended release for the management of chronic low back pain or osteoarthritis pain. Pain Pract 2010;10:416-27.

41. Buynak R, Shapiro DY, Okamoto A, et al. Efficacy and safety of tapentadol extended release for the management of chronic low back pain: results of a prospective, randomized, double-blind, placebo- and active-controlled phase III study. Expert Opin Pharmacother 2010;11:1787-804.

42. Wilkens P, Scheel IB, Grundnes O, Hellum C, Storheim K. Effect of glucosamine on pain-related disability in patients with chronic low back pain and degenerative lumbar osteoarthritis: a randomized controlled trial. JAMA 2010;304:45-52. 
43. Uberall MA, Mueller-Schwefe GH, Terhaag B. Efficacy and safety of flupirtine modified release for the management of moderate to severe chronic low back pain: results of SUPREME, a prospective randomized, double-blind, placebo- and active-controlled parallel-group phase IV study. Curr Med Res Opin 2012;28:1617-34.

44. Romano CL, Romano D, Bonora C, Mineo G. Pregabalin, celecoxib, and their combination for treatment of chronic low-back pain. J Orthop Traumatol 2009;10:185-91.

45. Urquhart DM, Hoving JL, Assendelft WW, Roland M, van Tulder MW. Antidepressants for nonspecific low back pain. Cochrane Database Syst Rev 2008;2008:CD001703.

46. Kumar S, Negi MP, Sharma VP, Shukla R, Dev R, Mishra UK. Efficacy of two multimodal treatments on physical strength of occupationally subgrouped male with low back pain. J Back Musculoskelet Rehabil 2009;22:179-88.

47. Ferreira ML, Ferreira PH, Latimer J, et al. Comparison of general exercise, motor control exercise and spinal manipulative therapy for chronic low back pain: a randomized trial. Pain 2007;131:31-7.

48. Koldaş Dogan S, Sonel Tur B, Kurtais Y, Atay MB. Comparison of three different approaches in the treatment of chronic low back pain. Clin Rheumatol 2008;27:873-81.

49. Clarke JA, van Tulder MW, Blomberg SE, et al. Traction for low-back pain with or without sciatica. Cochrane Database Syst Rev 2007;(2):CD003010.

50. Kuukkanen T, Malkia E, Kautiainen H, Pohjolainen T. Effectiveness of a home exercise programme in low back pain: a randomized five-year follow-up study. Physiother Res Int 2007;12:213-24.

51. Hall AM, Maher CG, Lam P, Ferreira M, Latimer J. Tai chi exercise for treatment of pain and disability in people with persistent low back pain: a randomized controlled trial. Arthritis Care Res (Hoboken) 2011;63:1576-83.

52. Jones MA, Stratton G, Reilly T, Unnithan VB. Recurrent non-specific low-back pain in adolescents: the role of exercise. Ergonomics 2007;50:1680-8.

53. Hurwitz EL, Morgenstern H, Chiao C. Effects of recreational physical activity and back exercises on low back pain and psychological distress: findings from the UCLA Low Back Pain Study. Am J Public Health
2005;95:1817-24.

54. Kader D, Radha S, Smith F, et al. Evaluation of perifacet injections and paraspinal muscle rehabilitation in treatment of low back pain: a randomised controlled trial. Ortop Traumatol Rehabil 2012;14:251-9.

55. Shirado O, Doi T, Akai M, et al. Multicenter randomized controlled trial to evaluate the effect of homebased exercise on patients with chronic low back pain: the Japan low back pain exercise therapy study. Spine (Phila Pa 1976) 2010;35:E811-9.

56. Sertpoyraz F, Eyigor S, Karapolat H, Capaci K, Kirazli Y. Comparison of isokinetic exercise versus standard exercise training in patients with chronic low back pain: a randomized controlled study. Clin Rehabil 2009;23:238-47.

57. Machado LA, Azevedo DC, Capanema MB, Neto TN, Cerceau DM. Client-centered therapy vs exercise therapy for chronic low back pain: a pilot randomized controlled trial in Brazil. Pain Med 2007;8:2518.

58. Jones M, Stratton G, Reilly T, Unnithan V. The efficacy of exercise as an intervention to treat recurrent nonspecific low back pain in adolescents. Pediatr Exerc Sci 2007;19:349-59.

59. Durmus D, Unal M, Kuru O. How effective is a modified exercise program on its own or with back school in chronic low back pain?: a randomizedcontrolled clinical trial. J Back Musculoskelet Rehabil 2014;27:553-61.

60. Bystrom MG, Rasmussen-Barr E, Grooten WJ. Motor control exercises reduces pain and disability in chronic and recurrent low back pain: a meta-analysis. Spine (Phila Pa 1976) 2013;38:E350-8.

61. Hayden JA, van Tulder MW, Malmivaara AV, Koes BW. Meta-analysis: exercise therapy for nonspecific low back pain. Ann Intern Med 2005;142:765-75.

62. Chou R, Huffman LH; American Pain Society; American College of Physicians. Nonpharmacologic therapies for acute and chronic low back pain: a review of the evidence for an American Pain Society/ American College of Physicians clinical practice guideline. Ann Intern Med 2007;147:492-504.

63. van Middelkoop M, Rubinstein SM, Verhagen AP, Ostelo RW, Koes BW, van Tulder MW. Exercise therapy for chronic nonspecific low-back pain. Best Pract Res Clin Rheumatol 2010;24:193-204.

64. Oesch P, Kool J, Hagen KB, Bachmann S. Effective- 
ness of exercise on work disability in patients with non-acute non-specific low back pain: systematic review and meta-analysis of randomised controlled trials. J Rehabil Med 2010;42:193-205.

65. Rhee HS, Kim YH, Sung PS. A randomized controlled trial to determine the effect of spinal stabilization exercise intervention based on pain level and standing balance differences in patients with low back pain. Med Sci Monit 2012;18:CR174-81.

66. Franca FR, Burke TN, Caffaro RR, Ramos LA, Marques AP. Effects of muscular stretching and segmental stabilization on functional disability and pain in patients with chronic low back pain: a randomized, controlled trial. J Manipulative Physiol Ther 2012;35:279-85.

67. Lewis JS, Hewitt JS, Billington L, Cole S, Byng J, Karayiannis S. A randomized clinical trial comparing two physiotherapy interventions for chronic low back pain. Spine (Phila Pa 1976) 2005;30:711-21.

68. Cairns MC, Foster NE, Wright C. Randomized controlled trial of specific spinal stabilization exercises and conventional physiotherapy for recurrent low back pain. Spine (Phila Pa 1976) 2006;31:E670-81.

69. Mohseni-Bandpei MA, Rahmani N, Behtash $\mathrm{H}$, Karimloo M. The effect of pelvic floor muscle exercise on women with chronic non-specific low back pain. J Bodyw Mov Ther 2011;15:75-81.

70. Bronfort G, Maiers MJ, Evans RL, et al. Supervised exercise, spinal manipulation, and home exercise for chronic low back pain: a randomized clinical trial. Spine J 2011;11:585-98.

71. Dundar U, Solak O, Yigit I, Evcik D, Kavuncu V. Clinical effectiveness of aquatic exercise to treat chronic low back pain: a randomized controlled trial. Spine (Phila Pa 1976) 2009;34:1436-40.

72. Tekur P, Singphow C, Nagendra HR, Raghuram N. Effect of short-term intensive yoga program on pain, functional disability and spinal flexibility in chronic low back pain: a randomized control study. J Altern Complement Med 2008;14:637-44.

73. Holtzman S, Beggs RT. Yoga for chronic low back pain: a meta-analysis of randomized controlled trials. Pain Res Manag 2013;18:267-72.

74. Bishop PB, Quon JA, Fisher CG, Dvorak MF. The Chiropractic Hospital-based Interventions Research Outcomes (CHIRO) study: a randomized controlled trial on the effectiveness of clinical practice guide- lines in the medical and chiropractic management of patients with acute mechanical low back pain. Spine J 2010;10:1055-64.

75. Juni P, Battaglia M, Nuesch E, et al. A randomized controlled trial of spinal manipulative therapy in acute low back pain. Ann Rheum Dis 2009;68:14207.

76. Goertz CM, Long CR, Hondras MA, et al. Adding chiropractic manipulative therapy to standard medical care for patients with acute low back pain: results of a pragmatic randomized comparative effectiveness study. Spine (Phila Pa 1976) 2013;38:627-34.

77. Eisenberg DM, Post DE, Davis RB, et al. Addition of choice of complementary therapies to usual care for acute low back pain: a randomized controlled trial. Spine (Phila Pa 1976) 2007;32:151-8.

78. Hurwitz EL, Morgenstern H, Kominski GF, Yu F, Chiang LM. A randomized trial of chiropractic and medical care for patients with low back pain: eighteen-month follow-up outcomes from the UCLA low back pain study. Spine (Phila Pa 1976) 2006;31:61122.

79. Nazzal ME, Saadah MA, Saadah LM, et al. Management options of chronic low back pain: a randomized blinded clinical trial. Neurosciences (Riyadh) 2013;18:152-9.

80. Henchoz Y, de Goumoens P, Norberg M, Paillex R, So AK. Role of physical exercise in low back pain rehabilitation: a randomized controlled trial of a threemonth exercise program in patients who have completed multidisciplinary rehabilitation. Spine (Phila Pa 1976) 2010;35:1192-9.

81. Anema JR, Steenstra IA, Bongers PM, et al. Multidisciplinary rehabilitation for subacute low back pain: graded activity or workplace intervention or both?: a randomized controlled trial. Spine (Phila Pa 1976) 2007;32:291-300.

82. Dufour N, Thamsborg G, Oefeldt A, Lundsgaard C, Stender S. Treatment of chronic low back pain: a randomized, clinical trial comparing group-based multidisciplinary biopsychosocial rehabilitation and intensive individual therapist-assisted back muscle strengthening exercises. Spine (Phila Pa 1976) 2010;35:469-76.

83. Monticone M, Ambrosini E, Rocca B, Magni S, Brivio F, Ferrante S. A multidisciplinary rehabilitation programme improves disability, kinesiophobia 
and walking ability in subjects with chronic low back pain: results of a randomised controlled pilot study. Eur Spine J 2014;23:2105-13.

84. Cecchi F, Molino-Lova R, Chiti M, et al. Spinal manipulation compared with back school and with individually delivered physiotherapy for the treatment of chronic low back pain: a randomized trial with oneyear follow-up. Clin Rehabil 2010;24:26-36.

85. Garcia AN, Costa Lda C, da Silva TM, et al. Effectiveness of back school versus McKenzie exercises in patients with chronic nonspecific low back pain: a randomized controlled trial. Phys Ther 2013;93:72947.

86. Morone G, Paolucci T, Alcuri MR, et al. Quality of life improved by multidisciplinary back school program in patients with chronic non-specific low back pain: a single blind randomized controlled trial. Eur J Phys Rehabil Med 2011;47:533-41.

87. Sahin N, Albayrak I, Durmus B, Ugurlu H. Effectiveness of back school for treatment of pain and functional disability in patients with chronic low back pain: a randomized controlled trial. J Rehabil Med 2011;43:224-9.

88. Devasahayam AJ, Lim CK, Goh MR, You JP, Pua PY. Delivering a back school programme with a cognitive behavioural modification: a randomised pilot trial on patients with chronic nonspecific low back pain and functional disability. Proc Singap Healthc 2014;23:218-25.

89. Hidalgo B, Detrembleur C, Hall T, Mahaudens P, Nielens $\mathrm{H}$. The efficacy of manual therapy and exercise for different stages of non-specific low back pain: an update of systematic reviews. J Man Manip Ther 2014;22:59-74.

90. Kumar S, Beaton K, Hughes T. The effectiveness of massage therapy for the treatment of nonspecific low back pain: a systematic review of systematic reviews. Int J Gen Med 2013;6:733-41.

91. Geisser ME, Wiggert EA, Haig AJ, Colwell MO. A randomized, controlled trial of manual therapy and specific adjuvant exercise for chronic low back pain. Clin J Pain 2005;21:463-70.

92. Furlan AD, Giraldo M, Baskwill A, Irvin E, Imamura M. Massage for low-back pain. Cochrane Database Syst Rev 2015;(9):CD001929.

93. Majchrzycki M, Kocur P, Kotwicki T. Deep tissue massage and nonsteroidal anti-inflammatory drugs for low back pain: a prospective randomized trial. ScientificWorldJournal 2014;2014:287597.

94. Wilkey A, Gregory M, Byfield D, McCarthy PW. A comparison between chiropractic management and pain clinic management for chronic low-back pain in a national health service outpatient clinic. J Altern Complement Med 2008;14:465-73.

95. Hawk C, Long CR, Rowell RM, Gudavalli MR, Jedlic$\mathrm{ka} \mathrm{J}$. A randomized trial investigating a chiropractic manual placebo: a novel design using standardized forces in the delivery of active and control treatments. J Altern Complement Med 2005;11:109-17.

96. Roelofs PD, Deyo RA, Koes BW, Scholten RJ, van Tulder MW. Nonsteroidal anti-inflammatory drugs for low back pain: an updated Cochrane review. Spine (Phila Pa 1976) 2008;33:1766-74.

97. Casserley-Feeney SN, Daly L, Hurley DA. The access randomized clinical trial of public versus private physiotherapy for low back pain. Spine (Phila Pa 1976) 2012;37:85-96.

98. Smeets RJ, Vlaeyen JW, Hidding A, et al. Active rehabilitation for chronic low back pain: cognitivebehavioral, physical, or both? First direct posttreatment results from a randomized controlled trial [ISRCTN22714229]. BMC Musculoskelet Disord 2006;7:5.

99. Tefner IK, Nemeth A, Laszlofi A, Kis T, Gyetvai G, Bender $\mathrm{T}$. The effect of spa therapy in chronic low back pain: a randomized controlled, single-blind, follow-up study. Rheumatol Int 2012;32:3163-9.

100. Weiner DK, Perera S, Rudy TE, Glick RM, Shenoy S, Delitto A. Efficacy of percutaneous electrical nerve stimulation and therapeutic exercise for older adults with chronic low back pain: a randomized controlled trial. Pain 2008;140:344-57.

101. Diab AA, Moustafa IM. The efficacy of lumbar extension traction for sagittal alignment in mechanical low back pain: a randomized trial. J Back Musculoskelet Rehabil 2013;26:213-20.

102. Diab AA, Moustafa IM. Lumbar lordosis rehabilitation for pain and lumbar segmental motion in chronic mechanical low back pain: a randomized trial. J Manipulative Physiol Ther 2012;35:246-53.

103. Ebadi S, Ansari NN, Naghdi S, et al. The effect of continuous ultrasound on chronic non-specific low back pain: a single blind placebo-controlled randomized trial. BMC Musculoskelet Disord 2012;13:192. 
104. Djavid GE, Mehrdad R, Ghasemi M, Hasan-Zadeh $\mathrm{H}$, Sotoodeh-Manesh A, Pouryaghoub G. In chronic low back pain, low level laser therapy combined with exercise is more beneficial than exercise alone in the long term: a randomized trial. Aust J Physiother 2007;53:155-60.

105. Cuesta-Vargas AI, Garcia-Romero JC, Arroyo-Morales M, Diego-Acosta AM, Daly DJ. Exercise, manual therapy, and education with or without high-intensity deep-water running for nonspecific chronic low back pain: a pragmatic randomized controlled trial. Am J Phys Med Rehabil 2011;90:526-34.

106. Wajswelner H, Metcalf B, Bennell K. Clinical pilates versus general exercise for chronic low back pain: randomized trial. Med Sci Sports Exerc 2012;44:1197205.

107. Marshall PW, Kennedy S, Brooks C, Lonsdale C. Pilates exercise or stationary cycling for chronic nonspecific low back pain: does it matter?: a randomized controlled trial with 6-month follow-up. Spine (Phila Pa 1976) 2013;38:E952-9.

108. van der Roer N, van Tulder M, Barendse J, Knol D, van Mechelen W, de Vet $\mathrm{H}$. Intensive group training protocol versus guideline physiotherapy for patients with chronic low back pain: a randomised controlled trial. Eur Spine J 2008;17:1193-200.

109. Magalhaes MO, Muzi LH, Comachio J, et al. The short-term effects of graded activity versus physiotherapy in patients with chronic low back pain: a randomized controlled trial. Man Ther 2015;20:603-9.

110. Seco J, Kovacs FM, Urrutia G. The efficacy, safety, effectiveness, and cost-effectiveness of ultrasound and shock wave therapies for low back pain: a systematic review. Spine J 2011;11:966-77.

111. Toomey E, Currie-Murphy L, Matthews J, Hurley DA. The effectiveness of physiotherapist-delivered group education and exercise interventions to promote self-management for people with osteoarthritis and chronic low back pain: a rapid review part I. Man Ther 2015;20:265-86.

112. Itoh K, Katsumi Y, Hirota S, Kitakoji H. Effects of trigger point acupuncture on chronic low back pain in elderly patients: a sham-controlled randomised trial. Acupunct Med 2006;24:5-12.

113. Koumantakis GA, Watson PJ, Oldham JA. Supplementation of general endurance exercise with stabilisation training versus general exercise only: physi- ological and functional outcomes of a randomised controlled trial of patients with recurrent low back pain. Clin Biomech (Bristol, Avon) 2005;20:474-82.

114. Kapural L, Vrooman B, Sarwar S, et al. A randomized, placebo-controlled trial of transdiscal radiofrequency, biacuplasty for treatment of discogenic lower back pain. Pain Med 2013;14:362-73.

115. Luedtke K, Rushton A, Wright C, et al. Effectiveness of transcranial direct current stimulation preceding cognitive behavioural management for chronic low back pain: sham controlled double blinded randomised controlled trial. BMJ 2015;350:h1640.

116. Manchikanti L, Cash KA, McManus CD, Pampati V, Benyamin RM. A randomized, double-blind, activecontrolled trial of fluoroscopic lumbar interlaminar epidural injections in chronic axial or discogenic low back pain: results of 2-year follow-up. Pain Physician 2013;16:E491-504.

117. Manchikanti L, Cash KA, McManus CD, Pampati V, Benyamin RM. Preliminary results of a randomized, double-blind, controlled trial of fluoroscopic lumbar interlaminar epidural injections in managing chronic lumbar discogenic pain without disc herniation or radiculitis. Pain Physician 2010;13:E279-92.

118. Sayegh FE, Kenanidis EI, Papavasiliou KA, Potoupnis ME, Kirkos JM, Kapetanos GA. Efficacy of steroid and nonsteroid caudal epidural injections for low back pain and sciatica: a prospective, randomized, double-blind clinical trial. Spine (Phila Pa 1976) 2009;34:1441-7.

119. Manchikanti L, Singh V, Falco FJ, Cash KA, Pampati V. Lumbar facet joint nerve blocks in managing chronic facet joint pain: one-year follow-up of a randomized, double-blind controlled trial: Clinical Trial NCT00355914. Pain Physician 2008;11:121-32.

120. Manchikanti L, Singh V, Falco FJ, Cash KA, Pampati V. Evaluation of lumbar facet joint nerve blocks in managing chronic low back pain: a randomized, doubleblind, controlled trial with a 2 -year follow-up. Int J Med Sci 2010;7:124-35.

121. Manchikanti L, Manchikanti KN, Manchukonda R, et al. Evaluation of lumbar facet joint nerve blocks in the management of chronic low back pain: preliminary report of a randomized, double-blind controlled trial: clinical trial NCT00355914. Pain Physician 2007;10:425-40.

122. Civelek E, Cansever T, Kabatas S, et al. Comparison 
of effectiveness of facet joint injection and radiofrequency denervation in chronic low back pain. Turk Neurosurg 2012;22:200-6.

123. Ribeiro LH, Furtado RN, Konai MS, Andreo AB, Rosenfeld A, Natour J. Effect of facet joint injection versus systemic steroids in low back pain: a randomized controlled trial. Spine (Phila Pa 1976) 2013;38:1995-2002.

124. Pach D, Brinkhaus B, Roll S, et al. Efficacy of injections with Disci/Rhus toxicodendron compositum for chronic low back pain: a randomized placebocontrolled trial. PLoS One 2011;6:e26166.

125. Friedman BW, Esses D, Solorzano C, et al. A randomized placebo-controlled trial of single-dose IM corticosteroid for radicular low back pain. Spine (Phila Pa 1976) 2008;33:E624-9.

126. Choi HJ, Hahn S, Kim CH, et al. Epidural steroid injection therapy for low back pain: a meta-analysis. Int J Technol Assess Health Care 2013;29:244-53.

127. Liu L, Skinner M, McDonough S, Mabire L, Baxter GD. Acupuncture for low back pain: an overview of systematic reviews. Evid Based Complement Alternat Med 2015;2015:328196.

128. Attal N, Cruccu G, Baron R, et al. EFNS guidelines on the pharmacological treatment of neuropathic pain: 2010 revision. Eur J Neurol 2010;17:1113.
129. Salzberg LD, Manusov EG. Management options for patients with chronic back pain without an etiology. Health Serv Insights 2013;6:33-8.

130. Dworkin RH, O’Connor AB, Backonja M, et al. Pharmacologic management of neuropathic pain: evidencebased recommendations. Pain 2007;132:237-51.

131. O'Connor AB, Dworkin RH. Treatment of neuropathic pain: an overview of recent guidelines. Am J Med 2009;122(10 Suppl):S22-32.

132. Kim K, Isu T, Kokubo R, et al. Therapeutic effect of mirogabalin on peripheral neuropathic pain due to lumbar spine disease. Asian Spine J 2021;15:349-56.

133. Bardin LD, King P, Maher CG. Diagnostic triage for low back pain: a practical approach for primary care. Med J Aust 2017;206:268-73.

134. Ruangchainikom M, Daubs MD, Suzuki A, et al. Patterns of lumbar disc degeneration: magnetic resonance imaging analysis in symptomatic subjects. Asian Spine J 2021;15:799-807.

135. Ogon I, Iba K, Takashima H, et al. Magnetic resonance spectroscopic analysis of multifidus muscle lipid contents and association with nociceptive pain in chronic low back pain. Asian Spine J 2021;15:441-6.

136. Tay M, Sian SC, Eow CZ, Ho KL, Ong JH, Sirisena D. Ultrasound-guided lumbar spine injection for axial and radicular pain: a single institution early experience. Asian Spine J 2021;15:216-23. 